\title{
ORIGINAL RESEAREH
}

\section{Comparative Evaluation of Carisolv with EDTA and Sodium hypochlorite in Removing the Smear Layer on Radicular Dentine using SEM -An In Vitro Study}

\author{
Bindu M. John ', Shashi Rashmi Acharya ${ }^{2}$, Vidya Saraswathi ${ }^{3}$, Carounanidy Usha ${ }^{4}$
}

\begin{abstract}
Back ground: Smear layer is a tough adherent layer on the instrumented radicular dentin composed of organic and inorganic debris. Removing this layer is imperative for disinfection and obturation of root canal. However no single irrigating solution is effective in removal of the smear layer . 5.25\% Sodium hypochlorite and 17\% EDTA have been proven to remove both the organic and the inorganic portion of the smear layer, when used alternatively. Carisolv ${ }^{\mathrm{TM}}$ is chemo mechanical agent in removal of caries which consists of $0.5 \%$ of Sodium hypochlorite and amino acids. This study aims to evaluate the efficacy of Carisolv ${ }^{\text {TM }}$ in removing the smear layer when compared with 17\% EDTA, 5.25\% Sodium hypochlorite and normal saline. Methodology: 80 roots were divided into 4 groups. All roots were prepared by step back technique and irrigated with various solutions. Roots in Group 1 was irrigated with $1 \mathrm{ml}$ of Carisolv ${ }^{\mathrm{TM}}$, in Group 2 with $1 \mathrm{ml}$ of $0.5 \%$ Sodium hypochlorite, in Group 3 with $1 \mathrm{ml}$ of $17 \%$ EDTA and in Group 4 with $1 \mathrm{ml}$ of saline. All the teeth were sectioned longitudinally and then horizontally to obtain middle and apical third sections. These samples were evaluated with SEM and the photomicrographs were scored according to a 5-point scale. The data was analysed by using chi square test at $\mathrm{p}<0.01$. Results: Carisolv ${ }^{\mathrm{TM}}$ was found to ineffective in removing the smear layer. $17 \%$ EDTA and 5.25\% Sodium hypochlorite were effective in removal but neither of them removed the layer completely when used
\end{abstract}

Key words: Carisolv ${ }^{\mathrm{TM}}$, smear layer, scanning electron microscope

The objective of root canal therapy is to create a favourable environment for healing and repair of the diseased periapical tissues. Such an outcome is achieved by the cleaning and shaping phase of root canal therapy, where the zone of infection in the root canals is removed and subsequently sealed in all three dimensions.

Cleaning and shaping of the root canals is done with the hand/ rotary instruments accompanied by copious irrigation with various irrigants. In the process of shaping the canal, hand and the rotary root canal instruments produce a thin layer of sludge that stubbornly coats the entire root canal and also extends into the depth of dentinal tubules to few millimetres. Routine irrigating protocols do not remove this debris easily. This layer is called as the smear layer.

The American Association of Endodontists, Endodontic glossary, define smear layer as "a surface film of debris retained on dentin and other surfaces after instrumentation with either rotary instruments or endodontic files; consist of dentin particles, remnants of vital or necrotic pulp tissue, bacterial components and

$$
\text { Received : 25.10.12 Accepted : } 12.12 .12
$$

retained irrigant." ${ }^{,[1]}$. It has an amorphous, irregular and granular appearance under SEM. The tooth particle size ranged from 0.5 to 15 microns. They also had globular subunits of $0.05-0.1$ microns of mineral component. The smear layer thickness ranged from 1-5 microns that varied with hand and rotary cutting instruments.

Smear layer consists of two layers; the superficial layer and a layer that is packed into the dentinal tubules. The smear layer plugs the dentinal tubules to a depth of 40 microns. This packing is attributed to the capillary action into the dentinal tubules as a result of adhesive forces between the smear layer and the dentinal debris ${ }^{[2]}$.

The removal of smear layer is a controversial concept and technically challenging step also. The reasons that favour the removal of the smear layer are as follows:

1. It acts as a barrier for the penetration of intra canal medicaments or the irrigants into the dentinal tubules.

2. It acts as an impediment to perfect adaptation of the obturating material, thus compromising the seal.

3. Loosely attached smear layer may disintegrate after 
obturation thus compromising the marginal integrity.

4. The micro-organisms present in the layer or the dentinal tubules may thrive and proliferate in the canal, thus re-establishing the zone of infection. ${ }^{[3]}$

The most commonly used irrigating solution is Sodium hypochlorite, which is a tissue dissolvent. ${ }^{[4]}$ It is highly effective in removing the organic debris. However, as the smear layer contains the inorganic component also, it is ineffective in completely removing the smear layer from the tubules. Chelating agent such as Ethylene Di-amine Tetra-acetic acid (EDTA) has been found to be effective in removing the inorganic content, by reacting with the calcium ions in dentine and by forming soluble calcium chelates ${ }^{[s]}$.

Thus a combination irrigation protocol, using 17\% EDTA and $5.25 \%$ of Sodium hypochlorite has been adopted to remove both the organic and inorganic component of the smear layer. ${ }^{[6,7]}$.

Incidentally Goldman et al ${ }^{[8]}$ at the same time, introduced the concept of chemical removal of caries with Sodium hypochlorite, based on its ability to remove organic debris. To reduce the corrosive effect of full strength sodium hypochlorite, it was buffered and diluted with a combination of Sodium hydroxide, Sodium chloride and glycine. Glycine was later replaced with aminobutyric acid. This system was called commercially as Caridex system. It involved elaborate equipment and was time consuming.

The next evolution in this series is Carisolv ${ }^{\mathrm{TM}}$, which incorporated amino acids (glutamic acid, luciene and lysine) into the combination. Carisolv ${ }^{\mathrm{TM}}$ (MediTeam, Sweden) is available as two syringes, one containing $0.5 \%$ Sodium hypochlorite solution and the other containing pink gel of the three amino acids. Carboxymethyl cellulose and erythrocin are also added to make the gel viscous ${ }^{[9]}$. The mode of action of this agent is to break down degraded collagen in demineralized dentine and dissolve carious dentine ${ }^{[10]}$.

Though 5.25\% Sodium hypochlorite is considered as an ideal irrigant, it also has toxic effects on vital tissues, resulting in haemolysis, skin ulceration and necrosis ${ }^{[11]}$. Therefore a widespread apprehension is present among clinician that has resulted in the usage of alternate irrigating solutions. Sodium hypochlorite itself has been evaluated in various concentrations ranging from $0.5 \%$ to $5 \%$ and it has been found to be effective even in low concentration by few studies ${ }^{[12]}$.

Carisolv $^{\mathrm{TM}}$ has also been evaluated for its efficacy to remove the smear layer when used as an endodontic irrigant because of its capacity to degrade the denatured collagen with the amino acid content and its low concentration of Sodium hypochlorite. However very limited evidence is available in the literature ${ }^{[13,14,15,16]}$.

Thus the purpose of this study was to evaluate the efficiency of Carisolv ${ }^{\mathrm{TM}}$ in removal of smear layer when compared with $0.5 \%$ Sodium hypochlorite, saline and $17 \%$ EDTA, using scanning electron microscope.

\section{MATERIALS AND METHODS}

Eighty single rooted extracted teeth were stored in $0.2 \%$ Chlorhexidine gluconate solution. All teeth were decoronated to obtain a root length of $12 \mathrm{~mm}$. Eighty roots were selected and orifices were widened using round bur and pulp remnants were removed using barbed broach. Working length was estimated by introducing $10 \mathrm{~K}-\mathrm{Flex}$ file into the canal till the file was visible at the apical foramen and then reducing $1 \mathrm{~mm}$ short from that point. These eighty roots were divided into four groups. Cleaning and shaping was done starting from $15 \mathrm{~K}-\mathrm{Flex}$ file up to $45 \mathrm{~K}$-Flex file.

Group 1 teeth were instrumented using $1 \mathrm{ml}$ of Carisolv ${ }^{\mathrm{TM}}$ (MediTeam, Sweden) as the irrigant (Fig 1).

Group 2 teeth were instrumented using $1 \mathrm{ml}$ of $0.5 \%$ of Sodium hypochlorite as the irrigant.

Group 3 teeth were instrumented using $1 \mathrm{ml}$ of $17 \%$ EDTA as the irrigant.

Group 4 teeth were instrumented using $1 \mathrm{ml}$ of normal

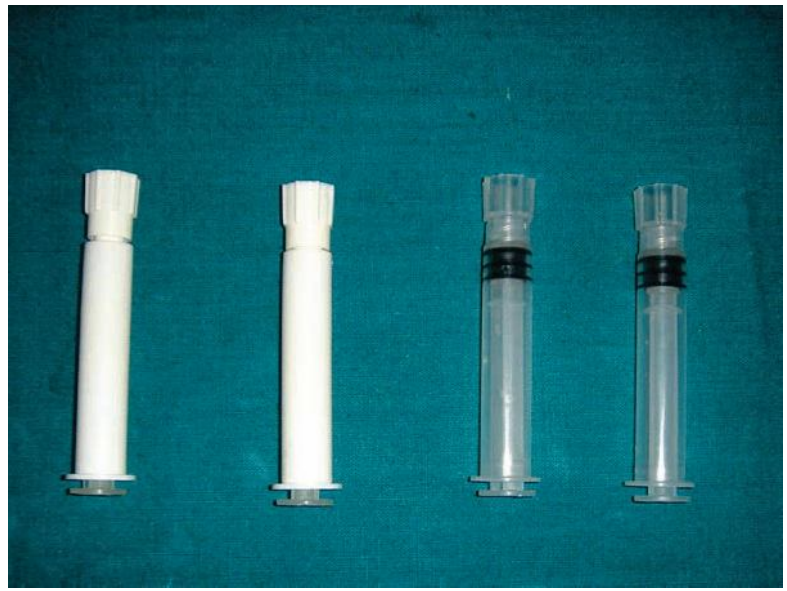

Fig 1 : Carisolv ${ }^{\mathrm{TM}}$ - Tubes containing the Sodium hypochlorite and the amino acids \begin{tabular}{l|l} 
Journal of Scientific Dentistry, 2(2), 2012 & 12
\end{tabular} 
saline as the irrigant which served as control.

As and when the canals were filled with these irrigating solutions, they were agitated using Sonic unit (MM3 Sonic) for $1 \mathrm{~min}$, after which the canals were refilled with the solutions and agitated in the same way at $1 \mathrm{~min}$ interval for 5 mins. The roots were finally rinsed with saline to be free of agents and then incubated at $37^{\circ} \mathrm{C}$ for 24 hours. They were then removed from the incubator and sectioned longitudinally with help of carborundum disc. Among the split samples, the sections that showed the entire canal length was chosen. Thus 10 sections were in each group were chosen for the evaluation. Further sectioning was done horizontally to obtain middle third and apical third sections. These samples were rinsed with distilled water and dehydrated in sequential order of $10 \%, 25 \%, 50 \%, 75 \%, 90 \%$ and $100 \%$ alcohol solutions at 15 minutes interval. They were mounted and gold sputtered for scanning electron microscope (SEM-JSM840A) evaluation at the middle thirds and apical thirds separately.

The Micrographs at $1000 \mathrm{x}$ and $3000 \mathrm{x}$ were analysed and scored against five-point scale for the smear layer removal $^{[16]}$ :

Score 1- No or very minor visible surface smear layer, all tubules open

Score 2- Slight/mild coverage of smear layer $<25 \%$ tubules covered.

Score 3- Moderate coverage of smear layer $>25 \%$ but $<50 \%$ tubules covered

Score 4 -Heavy coverage of smear layer $>50 \%$ but $<75 \%$ tubules covered.

Score 5-Very heavy coverage of smear layer, few or no tubules visible.

The scoring at middle third and apical third for all groups were tabulated. The statistical significance was assessed by chi square test at the $\mathrm{p}$ value $<0.5$.

\section{RESULTS}

Table I shows the percentage of removal of smear layer in the middle and apical third with Carisolv ${ }^{\mathrm{TM}}$ as the irrigant. SEM micrographs showed heavy and very heavy coverage of dentinal tubules in the middle and apical thirds. $65 \%$ and $70 \%$ heavy coverage was observed in the middle and apical third respectively. (Fig-2a and $2 b$ )
Table 2 shows the coverage observed in both the thirds while using $0.5 \%$ Sodium hypochlorite. The scoring from SEM showed all four degrees of coverage in various areas of middle and apical third. But almost $40 \%$ of the apical third of the canal showed only slight coverage with smear. In contrast $35 \%$ of the middle third was heavily covered with smear (Fig-3a and $3 b$ ).

Table 3 shows the smear removal with 17\% EDTA. Only slight coverage of the tubules was visualised in micrographs in apical third $(50 \%)$ and middle third $(85 \%)$ (Fig-4 a and $4 \mathrm{~b})$.

Table 4 shows the capacity of saline in removing the smear coverage and it was observed that $75 \%$ and $85 \%$ of very heavy coverage of the dentinal tubules were observed in the middle and apical third respectively (Fig-5a and $5 \mathrm{~b}$ ).

Table 5 and 6 shows the Chi-square value in the middle third and apical third respectively, when Carisolv group was compared with the other three groups. Fig- 8 shows the comparison of all the groups in a bar diagram.

The efficacy of smear layer removal of Carisolv was not statistically significant from saline but significantly different from $0.5 \%$ sodium hypochlorite and $17 \%$ EDTA. The $17 \%$ EDTA removed the smear layer more effectively than the other three.

\section{DISCUSSION}

The incidence of lateral and accessary canals is more in the apical and middle third regions of a root canal. ${ }^{[17]}$ Thus cleaning these regions is of paramount significance for a favorable outcome in root canal treatment.

A systematic review and meta-analysis of the influence of smear layer on the effect of obturation seal concluded that smear layer removal improves the fluid-tight seal of the root canal system whereas other factors such as the obturation technique or the sealer, did not produce significant effects ${ }^{[18]}$.

This study compared the efficacy of $0.5 \%$ Sodium hypochlorite, 17\% EDTA and normal saline irrigants with Carisolv ${ }^{\mathrm{TM}}$, which is an agent used in ultraconservative caries removal. Chemomechanical caries removal with CarisolvTM has been proven to be an effective alternate to conventional methods of caries removal $^{[19\rfloor}$. Carisolv ${ }^{\mathrm{TM}}$ contains $0.5 \%$ Sodium hypochlorite along with amino acids. Thus it was hypothesized that this agent can also be effective in 


\begin{tabular}{|l|c|c|}
\hline SCORE & MIDDLE THIRD & APICAL THIRD \\
\hline No/very minor & $0 \%$ & $0 \%$ \\
Light coverage debris $(<25 \%)$ & $0 \%$ & $0 \%$ \\
Moderate $(>25 \% \&<50 \%)$ & $0 \%$ & $0 \%$ \\
Heavy coverage $(>50 \% \&<75 \%)$ & $35 \%$ & $30 \%$ \\
Very high coverage & $65 \%$ & $70 \%$ \\
\hline
\end{tabular}

Table 1: Scoring of root sections in Carisolv ${ }^{\mathrm{TM}}$ Group ( Group 1)

\begin{tabular}{|l|c|l|}
\hline SCORE & MIDDLE THIRD & APICAL THIRD \\
\hline No/very minor & $0 \%$ & $0 \%$ \\
Light coverage debris $(<25 \%)$ & $20 \%$ & $40 \%$ \\
Moderate $(>25 \% \&<50 \%)$ & $25 \%$ & $15 \%$ \\
Heavy coverage $(>50 \% \&<75 \%)$ & $20 \%$ & $25 \%$ \\
Very high coverage & $35 \%$ & $20 \%$ \\
\hline
\end{tabular}

Table 2: Scoring of root sections in $0.5 \%$ Sodium hypochlorite Group ( Group 2)

\begin{tabular}{|l|c|l|}
\hline SCORE & MIDDLE THIRD & APICAL THIRD \\
\hline No/very minor & $15 \%$ & $0 \%$ \\
Light coverage debris $(<25 \%)$ & $85 \%$ & $50 \%$ \\
Moderate $(>25 \% \&<50 \%)$ & $0 \%$ & $40 \%$ \\
Heavy coverage $(>50 \% \&<75 \%)$ & $0 \%$ & $10 \%$ \\
Very high coverage & $0 \%$ & $0 \%$ \\
\hline
\end{tabular}

Table 3: Scoring of root sections in 17\% EDTA Group ( Group 3)

\begin{tabular}{|l|c|c|}
\hline SCORE & MIDDLE THIRD & APICAL THIRD \\
\hline No/very minor & $0 \%$ & $0 \%$ \\
Light coverage debris $(<25 \%)$ & $0 \%$ & $0 \%$ \\
Moderate $(>25 \% \&<50 \%)$ & $0 \%$ & $0 \%$ \\
Heavy coverage $(>50 \% \&<75 \%)$ & $25 \%$ & $15 \%$ \\
Very high coverage & $75 \%$ & $85 \%$ \\
\hline
\end{tabular}

Table 4: Scoring of root sections in Normal Saline Group ( Group 4)

\begin{tabular}{|l|l|l|}
\hline Carisolv vs sodium hypochlorite & Carisolv vs EDTA & Carisolv vs Saline \\
\hline $12.02 \mathrm{hs}$ & $40.00 \mathrm{vhs}$ & $0.476 \mathrm{~ns}$ \\
\hline
\end{tabular}

Table 5: Chi Square value $\left(X^{2}\right)$ in the middle third. $P$ value $<0.05$ hs - highly significant, vhs - very highly significant, ns - not significant

\begin{tabular}{|l|l|l|}
\hline Carisolv vs sodium hypochlorite & Carisolv vs EDTA & Carisolv vs Saline \\
\hline $19.54 \mathrm{hs}$ & $35.2 \mathrm{vhs}$ & $0.573 \mathrm{~ns}$ \\
\hline
\end{tabular}

Table 6: Chi Square value $\left(\mathrm{X}^{2}\right)$ in the apical third. $P$ value $<0.05$ hs - highly significant, vhs - very highly significant, ns - not significant 


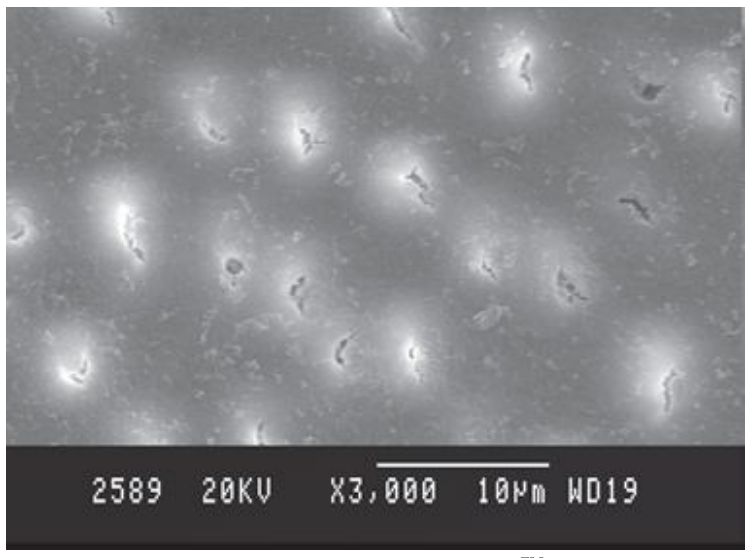

Fig 2a: Middle third of Carisolv ${ }^{\mathrm{TM}}$ group

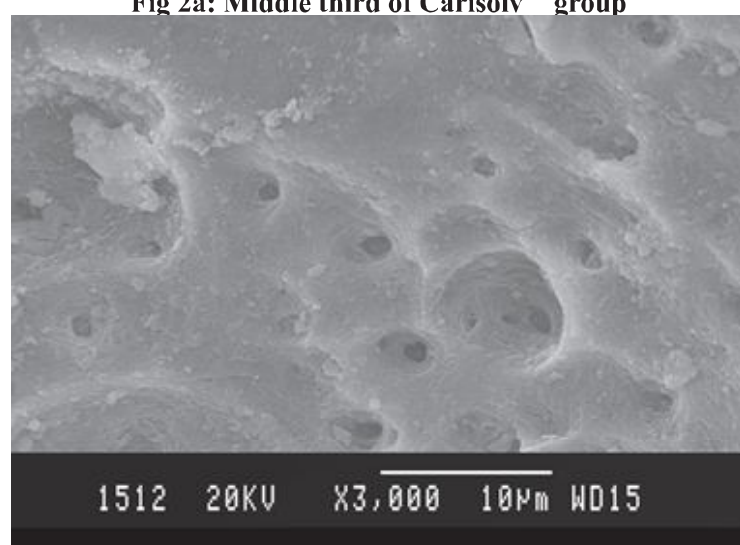

Fig 3a: Middle third of $\mathrm{NaOCl}$ group

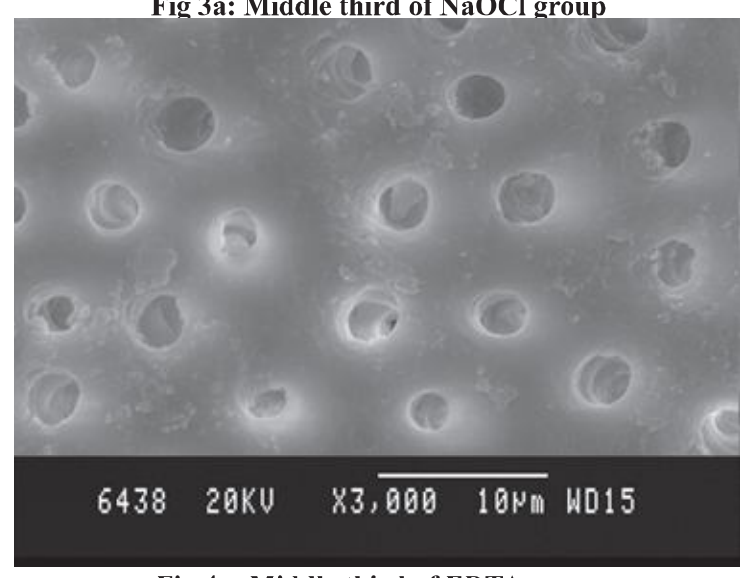

Fig 4a: Middle third of EDTA group

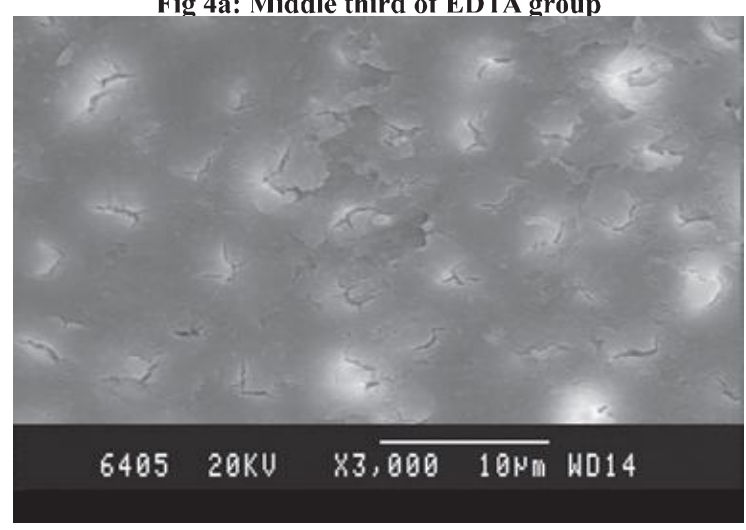

Fig 5a: Middle third of Saline group

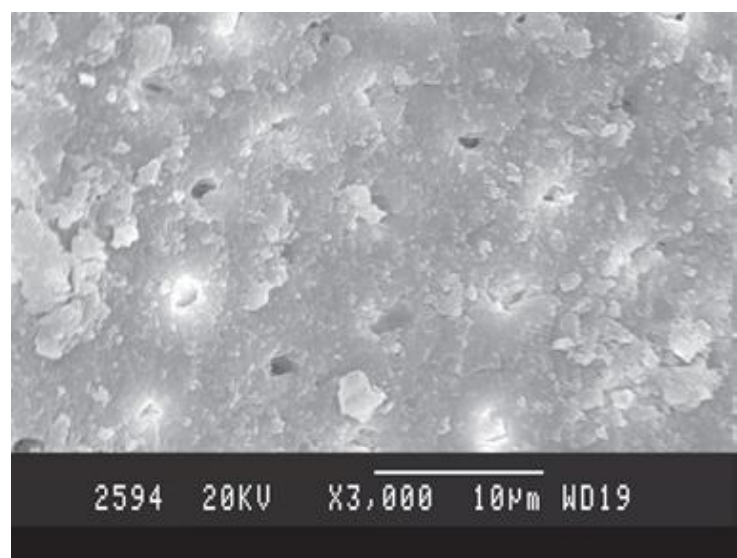

Fig 2b: Apical third of Carisolv ${ }^{\mathrm{TM}}$ group

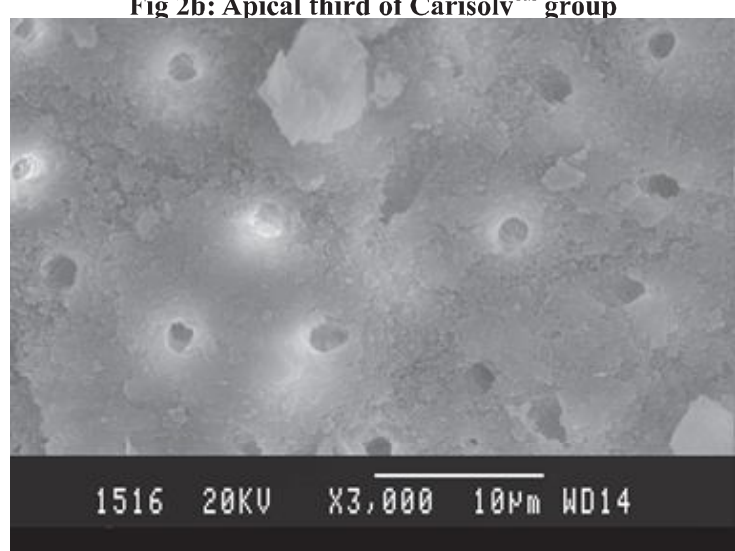

Fig 3b: Apical third of $\mathrm{NaOCl}$ group

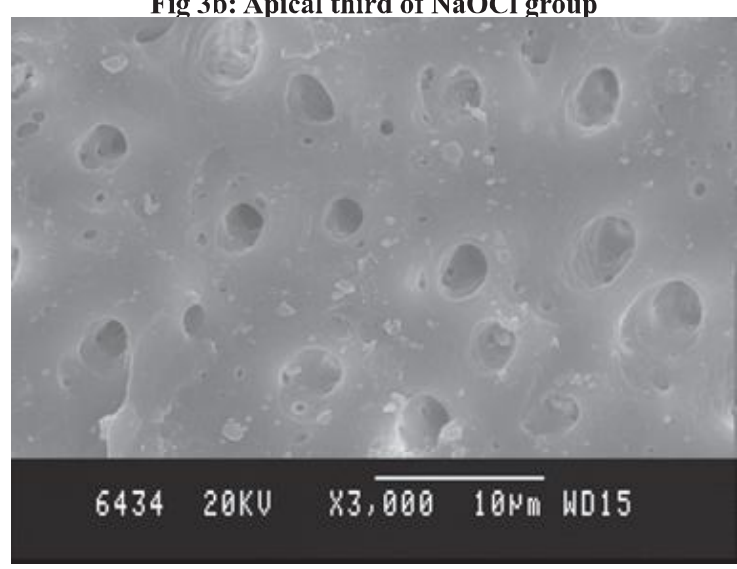

Fig 4b: Apical third of EDTA group

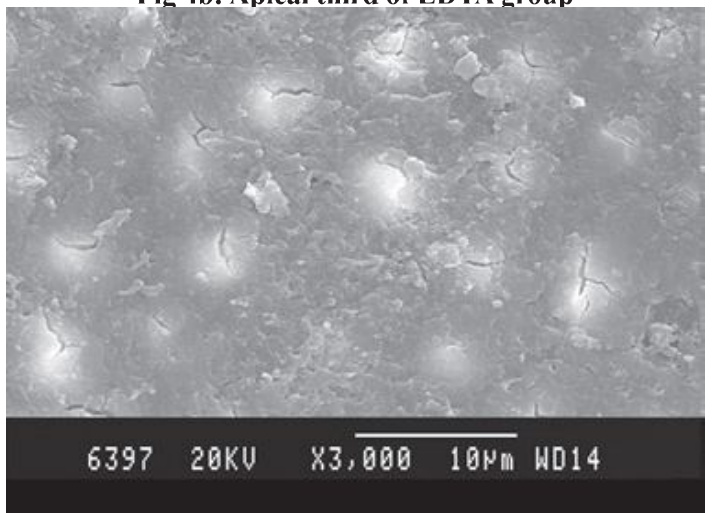

Fig 5b: Apical third of Saline group

15 Journal of Scientific Dentistry, 2(2), 2012 


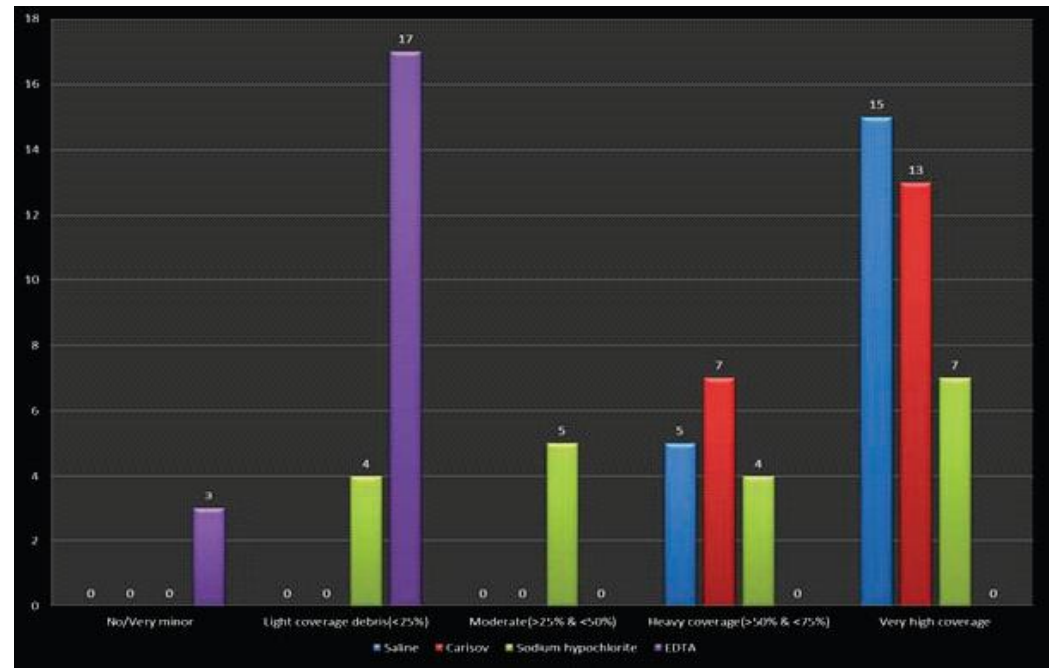

Fig 6: Bar Diagram depicting the scoring of all the groups at the middle third

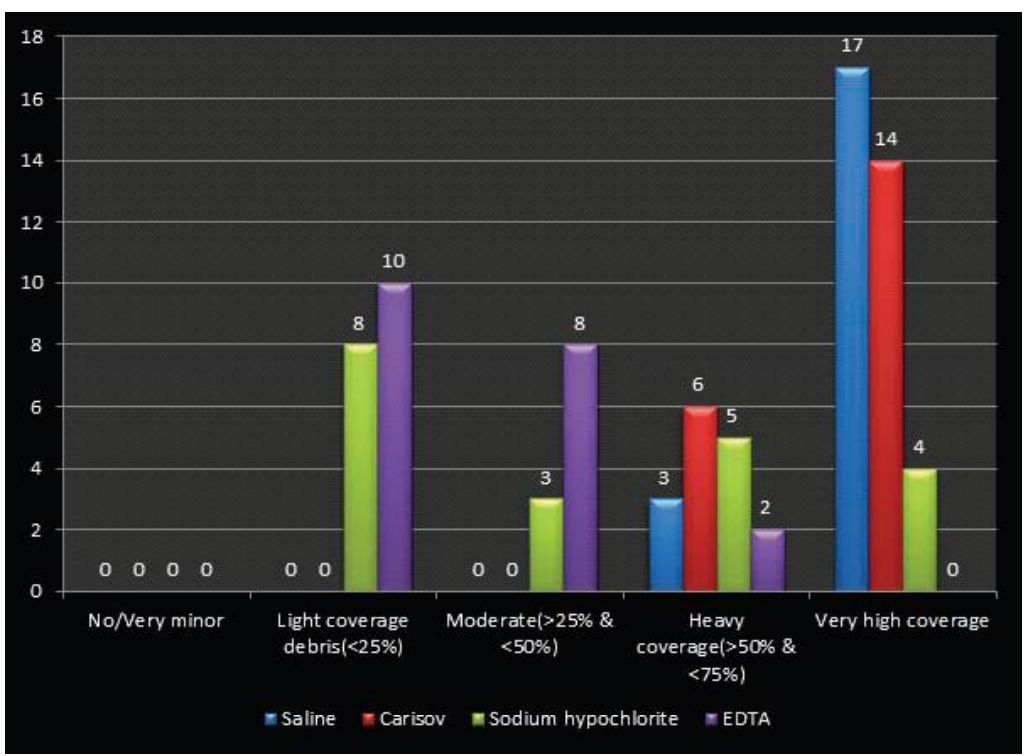

Fig 7: Bar Diagram depicting the scoring of all the groups at the apical third

removal of smear layer in root canal when used as an irrigant.

Sonic and ultrasonic irrigation has been reported to result in better removal of the smear layer in the apical third of curved root canals than did conventional irrigation ${ }^{[20]}$. Thus in this study the sonic agitation with MM3 sonic was done for 1 minute for all chemicals.

Scanning Electron microscopy is one the effective qualitative tool to study the surface morphology ${ }^{[21]}$. The dentinal tubules are very well appreciated in $1000 \mathrm{x}$ and $3000 \mathrm{x}$ magnification. The samples were evaluated using SEM and scoring was done on a five-point scale ${ }^{[16]}$.

The results of the study proved $17 \%$ EDTA to be a better solution for removal of smear layer. The difference between Carisolv ${ }^{\mathrm{TM}}$ and EDTA was statistically significant. EDTA's action is attributed to its capacity to chelate the inorganic portion of the smear and thus facilitate its easy removal. However this solution was not completely effective in removing smear layer from the middle and apical third. This may be due to the fact that EDTA cannot remove the organic portion of the smear ${ }^{[22]}$.

Sodium hypochlorite in $0.5 \%$ did not yield good results in smear layer removal in spite of sonic agitation. A concentration of $5.25 \%$ is considered toxic in spite of excellent tissue dissolving effect. Thus $1 \%$ Sodium hypochlorite is favored more as an irrigant since it is less toxic as well as effective in cleansing organic debris ${ }^{[23]}$. 
However statistically significant difference was observed when compared with Carisolv ${ }^{\mathrm{TM}}$ as far as smear layer removal.

Saline was used in this study as a negative control as it does not possess any of the requirements of an irrigant. The results showed that saline and Carisolv ${ }^{\mathrm{TM}}$ were equally ineffective in removing the smear layer in this study, in spite of Carisolv ${ }^{\mathrm{TM}}$ containing $0.5 \%$ Sodium hypochlorite. This can be attributed to the fact that Carisolv ${ }^{\mathrm{TM}}$ is in the form of a gel when the two tubes are mixed, which makes it difficult to wet and flush the canals, inspite of agitation. It is an established fact that the mechanical action of the irrigating solution is an equally important factor that influences their performance $^{[24]}$.

Results of similar studies on Carisolv ${ }^{\mathrm{TM}}$ are in accordance with the results of this study ${ }^{[14,15,16]}$.

\section{CONCLUSION}

No single irrigating solution is available as an ideal one that can remove the organics debris, act against the root canal microbiota as well as remove the smear layer. However various irrigants are available which have their unique attributes. A prudential combination of these solutions is now being advocated to combine their merits and combat the challenges in the root canal.

Carisolv $^{\mathrm{TM}}$, though is an effective chemo-mechanical agent in ultraconservative caries removal, within the scope of this in vitro study, it can be concluded that it is not effective in smear layer removal when used as root canal irrigant.

\section{REFERENCES}

1. http://www.nxtbook.com/nxtbooks/aae/ endodonticglossary/index.php\#/46

2. Sen BH, Wesselink PR, Türkün M. The smear layera phenomenon in root canal therapy. Int Endod J 1995;28(3):141-48.

3. Violich DR, Chandler NP. The smear layer in endodontics - a review. Int Endod J 2010; 43:2-15.

4. Zehnder M. Root canal irrigants. J Endod 2006;32(5):389-98.

5. McComb D, Smith DC. A preliminary scanning electron microscopic study of root canals after endodontic procedures. J Endod 1975;1(7):238-42.
6. Yamada RS, Armas A, Goldman M, Lin PS. A scanning electron microscopic comparison of a high volume final flush with several irrigating solutions: Part 3. J Endod 1983;9(4):137-42.

7. Goldman M, Goldman LB, Cavaleri R. The efficacy of several endodontic irrigating solutions - SEM study. J Endod 1982;8:487-92.

8. Goldman M, Kronman JH. A preliminary report on a chemomechanical means of removing caries. J Am Dent Assoc 1976;93:1149-53.

9. Elkholany NR, Abdelaziz KM, Zaghloul NM, Aboulenine N. Chemo-mechanical method: A valuable alternative for caries removal. J Minim Interv Dent 2009; 2 (4): 248-59.

10. Schutzbank SG, Galaini J, Goldman M . Comparative in vitro study of GK-101 and GK-101E in caries removal. J Dent Res 1978; 57:861-65.

11. Hülsmann M, Hahn W. Complications during root canal irrigation--literature review and case reports. Int Endod J 2000;33(3): 186-93.

12. Siqueira JF Jr, Machado AG, Silveira RM, Lopes HP, de Uzeda M. Evaluation of the effectiveness of sodium hypochlorite used with three irrigation methods in the elimination of Enterococcus faecalis from the root canal - An in vitro study. Int Endod J 1997;30(4):279-82.

13. Singhal P, Das UM, Vishwanathan D, Singhal A. Carisolv as an endodontic irrigant in deciduous teeth: an SEM study. Indian J Dent Res 2012; 23(1):120-21.

14. Antonio AG, Maia LC, Primo LG, Moraes RS, Cunha CB. The role of Carisolv and different auxiliary chemical substances in the removal of bovine root canal smear layer. J Oral Sci 2006; 48(3):99-103.

15. Rahman S, Whitworth JM, Dummer PM. Carisolv: an alternative to $\mathrm{NaOCl}$ in immature root canals. Int Endod J 2005; 38(7):448-55.

16. Al-Kilani MG, Whitworth JM, Dummer PM. Preliminary in vitro evaluation of Carisolv as a root canal irrigant. Int Endod J 2003; 36(6):433-40.

17. Cantatore G, Berutti E, Castellucci A. Missed anatomy: frequency and clinical impact. Endodontic Topics 2009;15:3-31. 
18. Shahravan A, Haghdoost AA, Adl A, Rahimi H, Shadifar F. Effect of smear layer on sealing ability of canal obturation: a systematic review and meta analysis. J Endod 2007;33(2):96-105.

19. Lozano-Chourio MA, Zambrano O, González H, Quero M. Clinical randomized controlled trial of chemomechanical caries removal (Carisolv). Int $\mathbf{J}$ Paediatr Dent 2006;16(3):161-67.

20. Blank-Gonçalves LM, Nabeshima CK, Martins GH, Machado ME. Qualitative analysis of the removal of the smear layer in the apical third of curved roots: Conventional irrigation versus activation systems. J Endod 2011;37(9):1268-71.

21. Saghiri MA, Asgar K, Lotfi M, Karamifar K, Saghiri AM, Neelakantan P, Gutmann JL, Sheibaninia A.
Back-scattered and secondary electron images of scanning electron microscopy in dentistry: a new method for surface analysis Acta Odontol Scand 2012;70(6):603-9.

22. Hülsmann M, Heckendorff M, Lennon A. Chelating agents in root canal treatment: mode of action and indications for their use. Int Endod J 2003;36(12):810-30.

23. Haapasalo M, Shen Y, Qian W, Gao Y. Irrigation in Endodontics. Dent Clin NAm 2010;54:291-312.

24. Abou Ross M. Effectiveness of four irrigation methods on the removal of root canal debris. Oral Sug 1982;54(3):323-8.
Address for correspondence:

Dr. Bindu M John

Senior Lecturer

Conservative Dentistry and Endodontics

Indira Gandhi Institute of Dental Sciences

Sri Balaji Vidyapeeth

Pondy-Cuddalore Main road

Pillayarkuppam,

Pondicherry - 607402

\section{Authors:}

${ }^{1}$ Senior Lecturer, ${ }^{4}$ Professor, Conservative Dentistry and Endodontics, IGIDS, SBV, Puducherry

${ }^{2}$ Professor, ${ }^{3}$ Professor and Head, Conservative Dentistry and Endodontics, CODS, Manipal.

\section{How to cite this article:}

Bindu M John. Comparative evaluation of Carisolv ${ }^{\mathrm{TM}}$ with EDTA and Sodium hypochlorite in removing the smear layer on radicular dentine using SEM-An in vitro study. Journal of Scientific Dentistry 2012;2(2):11-18.

Source of Support: Nil, Conflict of Interest: None declared 